\title{
FungalRV: adhesin prediction and immunoinformatics portal for human fungal pathogens
}

\author{
Rupanjali Chaudhuri, Faraz Alam Ansari, Muthukurussi Varieth Raghunandanan and Srinivasan Ramachandran*
}

\begin{abstract}
Background: The availability of sequence data of human pathogenic fungi generates opportunities to develop Bioinformatics tools and resources for vaccine development towards benefitting at-risk patients.

Description: We have developed a fungal adhesin predictor and an immunoinformatics database with predicted adhesins. Based on literature search and domain analysis, we prepared a positive dataset comprising adhesin protein sequences from human fungal pathogens Candida albicans, Candida glabrata, Aspergillus fumigatus, Coccidioides immitis, Coccidioides posadasii, Histoplasma capsulatum, Blastomyces dermatitidis, Pneumocystis carinii, Pneumocystis jirovecii and Paracoccidioides brasiliensis. The negative dataset consisted of proteins with high probability to function intracellularly. We have used 3945 compositional properties including frequencies of mono, doublet, triplet, and multiplets of amino acids and hydrophobic properties as input features of protein sequences to Support Vector Machine. Best classifiers were identified through an exhaustive search of 588 parameters and meeting the criteria of best Mathews Correlation Coefficient and lowest coefficient of variation among the 3 fold cross validation datasets. The "FungalRV adhesin predictor" was built on three models whose average Mathews Correlation Coefficient was in the range $0.89-0.90$ and its coefficient of variation across three fold cross validation datasets in the range $1.2 \%-2.74 \%$ at threshold score of 0 . We obtained an overall MCC value of 0.8702 considering all 8 pathogens, namely, C. albicans, C. glabrata, A. fumigatus, B. dermatitidis, C. immitis, C. posadasii, H. capsulatum and $P$. brasiliensis thus showing high sensitivity and specificity at a threshold of 0.511 . In case of $P$. brasiliensis the algorithm achieved a sensitivity of $66.67 \%$. A total of 307 fungal adhesins and adhesin like proteins were predicted from the entire proteomes of eight human pathogenic fungal species. The immunoinformatics analysis data on these proteins were organized for easy user interface analysis. A Web interface was developed for analysis by users. The predicted adhesin sequences were processed through 18 immunoinformatics algorithms and these data have been organized into MySQL backend. A user friendly interface has been developed for experimental researchers for retrieving information from the database.
\end{abstract}

Conclusion: FungalRV webserver facilitating the discovery process for novel human pathogenic fungal adhesin vaccine has been developed.

\section{Background}

As cases of immunosuppression rise, the spectrum of fungal pathogens is increasing thus posing a serious threat to human health. In the USA and in most European countries infection due to Candida species have become very common [1]. Amongst the Candida spp, C. albicans and C. glabrata account for approximately

\footnotetext{
* Correspondence: ramuigib@gmail.com

G.N Ramachandran Knowledge Centre for Genome Informatics, Institute of Genomics and Integrative Biology, Mall Road, Delhi 110007, India
}

70-80\% of Candida species recovered from patients with candidemia or invasive candidiasis [2,3]. Another pathogenic fungi, A. fumigatus is the most common life-threatening aerial fungal pathogen which primarily affects the lungs. In severe invasive aspergillosis caused mainly in immunocompromised individuals, the fungus can transfer from lungs through blood stream to brain and other organs. This condition of invasive aspergillosis is often associated with significant mortality and morbidity $[4,5]$. In addition, certain non-life-threatening superficial and
C Biomed Central

(c) 2011 Chaudhuri et al; licensee BioMed Central Ltd. This is an Open Access article distributed under the terms of the Creative Commons Attribution License (http://creativecommons.org/licenses/by/2.0), which permits unrestricted use, distribution, and reproduction in any medium, provided the original work is properly cited. 
respiratory infections caused by dimorphic pathogenic fungi like $C$. immitis, $H$. capsulatum, $P$. brasiliensis and $B$. dermatitidis impose significant restrictions on patients, resulting in a reduced quality of life. In some cases these infections may turn to life threatening specially in immunocompromised patients, where the infection spreads beyond the respiratory system to other parts of the body [6-10]. Another fungal infection Pneumocystis pneumonia (PCP) or pneumocystosis caused by unusual unicellular fungi Pneumocystis jirovecii (formerly called Pneumocystis carinii) is the most common opportunistic infection in persons with HIV infection [11].

It is challenging to identify candidates for vaccines in case of fungal infections because of their occurrence in immunocompromised or otherwise debilitated host. Yet it is being realized that either a preventive or therapeutic vaccine could be useful for at-risk patients $[12,13]$.

Adhesins are important virulence factors used by pathogens during establishment of infection. Therefore, targeting the adhesins in vaccine development can help efficiently combat fungal infections by blocking their function and preventing adherence to host cell [14]. A few vaccine formulations using adhesins as immunizing agents and are under evaluation include agglutinin-like sequence proteins in Candida albicans [15,16], BAD-1 (WI adhesin) protein in Blastomyces dermatitidis [17,18], $43 \mathrm{kDa}$ glycoprotein in Paracoccidioides brasiliensis $[19,20]$ and spherule outer wall glycoprotein in Coccidioides immitis [21,22]. Among these, the spherule outer wall glycoprotein in Coccidioides immitis has undergone trial in humans, while others have proved their efficacy in mouse experimental models.

Most fungal adhesins have a general structure consisting of an $\mathrm{N}$-terminal carbohydrate or peptide-binding domain, central Ser-Thr rich glycosylated domains and $\mathrm{C}$-terminal region mediating covalent cross-linking to the wall through modified glycosylphosphatidylinositol (GPI) anchors [23,24]. Others such as WI-1/Bad1 adhesin (from $B$. dermatiditis), Int1p adhesin (from $C$. albicans) do not conform to this general structure thereby causing difficulty in their identification. Using similarity search approach, Weig et al. (2004) and Butler et al. (2009) identified adhesins and GPI-anchored proteins in certain fungal pathogens $[25,26]$. These efforts can be complemented using machine learning techniques trained on compositional properties in the identification of novel adhesins because in principle, this approach allows development of a non-homology composition based method. The similarity based approach in principle enable identifying members of related family whereas the non-homology composition based method has potential to identify other novel members. Algorithms based on compositional properties for adhesin identification in different pathogenic species such as Plasmodium and bacteria have been useful $[27,28]$, encouraging us to attempt to develop a similar method for fungal species. Here, we present an algorithm developed by using Support Vector Machine trained through a combination of 3945 compositional properties for classifying human pathogenic fungal adhesins and adhesin like proteins. The predictions from these algorithms can be integrated with the immunoinformatics algorithms to facilitate rational vaccine development using reverse vaccinology $[29,30]$. The immunoinformatics data on the predicted fungal adhesins and adhesin like proteins are also organized for easy analysis and retrieval. These resources are made available through a user friendly interface FungalRV.

\section{Construction and Content \\ Dataset Preparation \\ Positive Dataset}

Through literature survey we collected known human pathogenic fungal adhesin protein sequences from C. albicans, C. glabrata, A. fumigatus, B. dermatitidis, C. immitis, C. posadasii, H. capsulatum, P. brasiliensis, $P$. jirovecii and P. carinii. In C. glabrata proteins having PA14 and GLEYA adhesin domain were also included $[31,32]$. Sequences were collected from the National Center for Biotechnology Information (NCBI) [33], Candida Genome Database (CGD) [34] and Swiss-Prot Databases [35].

\section{Negative Dataset}

Protein sequences which are not likely to be on the surface, or associated with adhesion were collected from NCBI, CGD and Swiss-Prot using keywords 'dehydratase', 'ribosomal protein', 'kinase', 'polymerase', 'acylCoA synthase', 'decarboxylase', and 'hydrolase'. Poorly annotated sequences were not considered. Pfam domain search was performed on negative dataset sequences. The results were analyzed exhaustively and any extracellular location associated domain containing protein sequence in the negative dataset was excluded. 'See additional file 1: Pfam domain search result of negative dataset'.

\section{Proteomes}

Proteomes of freely available fungal pathogens were sourced from various databases listed in Table 1. [36-38]

\section{Rendering datasets nonredundant}

The stringent criterion $(\mathrm{S}=100, \mathrm{~L}=1, \mathrm{~b}=\mathrm{T})$ specified in the BLASTCLUST computer program was used to identify redundancy. Redundant entries were removed using Shell scripts. The final positive dataset had 101 non redundant adhesin protein sequences and the negative dataset had 2644 non redundant protein sequences. 
Table 1 List of databases from which the human pathogenic fungal proteomes were sourced

\begin{tabular}{lll}
\hline Species & Source & Reference \\
\hline Candida albicans (21 ${ }^{\text {st }}$ assembly) & $\begin{array}{l}\text { Candida Genome } \\
\text { Database }\end{array}$ & {$[34,26]$} \\
\hline Candida glabrata & Genolevures & {$[36,26]$} \\
\hline Aspergillus fumigatus & J. Craig Venter Institute & {$[37]$} \\
\hline Coccidioides immitis RMSCC 2394 & Broad Institute & {$[38,26]$} \\
\hline Coccidioides posadasii Silveira & Broad Institute & {$[38,26]$} \\
\hline Histoplasma capsulatum Nam1 & Broad Institute & {$[38,26]$} \\
\hline Paracoccidioides brasiliensis Pb01 & Broad Institute & {$[38,26]$} \\
\hline Blastomyces dermatitidis SLH14081 & Broad Institute & {$[38,26]$} \\
\hline Candida dubliniensis & Sanger Institute & {$[26]$} \\
\hline Candida tropicalis & Broad Institute & {$[38,26]$} \\
\hline Candida parapsilosis & Broad Institute & {$[38,26]$} \\
\hline Candida lusitaniae & Broad Institute & {$[38,26]$} \\
\hline Candida guilliermondii & Broad Institute & {$[38,26]$} \\
\hline
\end{tabular}

\section{Compositional Attributes Used}

After several attempts using different combinations of compositional properties, we finally settled on the following:

\section{Amino acid frequencies}

$$
\mathrm{fi}(\mathrm{a})=\mathrm{Xi} / \mathrm{L}
$$

$\mathrm{Xi}$ is the counts of $\mathrm{i}^{\text {th }}$ amino acid in the sequence, $\mathrm{i}=$ $1, \ldots, 20$ for each of the amino acid type and $L$ is the length of the protein. There are 20 possible values for fi (a) for 20 amino acids.

\section{Multiplet frequencies}

Multiplets are defined as homopolymeric stretches (X)n where $X$ is the amino acid and $n$ (integer) $\geq 2$ [39]. After identification of all the multiplets, the frequencies of the amino acids in the multiplets were computed as follows:

$$
\text { fi }(\mathrm{m})=\mathrm{Xmi} / \mathrm{L} \text {. }
$$

$\mathrm{Xmi}$ is the counts of $\mathrm{i}^{\text {th }}$ amino acid occurring as multiplet. There are 20 possible values for fi $(\mathrm{m})$ for each of the 20 amino acids; and $\mathrm{L}$ is the length of the protein.

\section{Dipeptide frequencies}

The frequency of a dipeptide $(i, j)$,

$$
f i j=\left[\left(\text { counts of } \mathrm{ij}^{\text {th }} \text { dipeptide }\right) * 100 /(\mathrm{L}-1)\right] / 2 \text {, }
$$

where $i, j=1 . . .20$ for each of the 20 amino acids and $\mathrm{L}$ is the length of the sequence. The best dipeptides discriminators between positive and negative sets were identified with the help of Welch's t test in R statistical software (ver 2.9.2) [40]. Top 247 dipeptides were selected at cutoff significance at P-value $<0.001$.

\section{Tripeptide frequencies}

The frequency of a tripeptide (i, j, k),

$$
\text { fijk }=\left[\left(\text { counts of } \mathrm{ijk}^{\text {th }} \text { tripeptide }\right) * 100 /(\mathrm{L}-2)\right] / 3
$$

where $\mathrm{i}, \mathrm{j}, \mathrm{k}=1-20$. The best tripeptides discriminators between positive and negative sets were identified with the help of Welch's t test in R statistical software (ver 2.9.2) [40]. Top 3653 tripeptides were selected at cutoff significance at P-value $<0.001$.

\section{Hydrophobic Composition}

Each amino acid is given a hydrophobicity score between +4.5 and -4.5 according to Kyte and Doolittle hydrophobicity scale [41]. A score of +4.5 is the most hydrophobic and a score of -4.5 is the most hydrophilic. The hydrophobic amino acids with positive score A, M, C, F, L, V, I were selected. The frequency of hydrophobic amino acids (A, M, C, F, L, V, I) is given by,

$$
f_{\mathrm{h}}=\text { (counts of any of the } 7 \text { hydrophobic amino acids) } / \mathrm{L}
$$

where $\mathrm{L}$ is the length of the protein. Furthermore, information on the characteristics of the distribution of these amino acids in a given protein sequence was obtained by computing the moments of the positions of the occurrences of these amino acids. The general expression to compute moments of a given order; say ' $r$ ' is,

$\mathrm{Mr}=\mathrm{r}$-th order moment of the positions of hydrophobic amino acids

$$
=\sum\left(X_{i}-X_{m}\right)^{\mathrm{r}} / \mathrm{N},
$$

Where, $X_{m}=\sum_{i=1}^{N} X i / N$

$X_{m}$ is the mean of sequence positions of all hydrophobic amino acids, $X i$ is the sequence position of the $\mathrm{i}^{\text {th }}$ hydrophobic amino acid where $\mathrm{i}$ is any of the 7 hydrophobic amino acids A, M, C, F, L, V, I; and $\mathrm{N}$ is the total number of hydrophobic amino acids in the sequence and $r$ is from 2-5. The values of the $r^{\text {th }}$ order moments were downscaled to smaller decimal values by dividing by $(1000)^{\mathrm{r}}$ while preparing the feature input to SVM.

Thus, a total of 3945 compositional properties included amino acid frequencies of 20 from amino acids, 247 selected dipeptide frequencies, 3653 selected tripeptide frequencies, 20 amino acid multiplets frequencies, frequency of the hydrophobic amino acids and moments of hydrophobic amino acid distribution of order from 2-5.

Each sequence is represented by 3945 features. Programs in $C$ language were written to calculate these compositional properties. These compositional 
properties will serve as an input for the machine learning algorithm SVM.

\section{SVM implementation}

SVM is a supervised machine learning algorithm first introduced by Vapnik [42] used for problems involving classification and regression. In this study SVM was implemented using SVM ${ }^{\text {light }}$ package written and distributed by Thorsten Joachims [43]. This package has two modules svm_learn and svm_classify.

svm_learn: svm_learn is used prepare models(classifiers) built by learning from the training sets- positively and negatively labeled datasets labeled +1 and -1 respectively.

svm_classify: svm_classify is used by the models(classifiers) generated by svm_learn to classify the test set sequences (labeled 0 ).

\section{Training and Testing process}

The model (classifiers) are built using svm_learn module of SVM ${ }^{\text {light }}$. The training set was a file containing positively and negatively labeled samples labeled +1 and -1 respectively mixed in alternating order. Each positive sample corresponding to a positive protein sequence had +1 label followed by 3945 compositional properties. Similarly each negative sample has -1 label followed by 3945 compositional properties.

We have used two types of kernel functions, the polynomial function and the radial basis function (RBF). For polynomial kernel, all the SVM parameters were set to default, except $d$ and $C$, the trade-off between training error and margin. The scalable memory parameter $(\mathrm{m})$ was fixed to 120 . The values for $\mathrm{d}$ and $\mathrm{C}$ were incremented stepwise through a combination of $1,2,3,4$. . to ... 9 for $\mathrm{d}$, and $10^{-5}$ to. . $10^{15}$ for C. For the RBF kernel, the parameter gamma $\mathrm{g}$ and $\mathrm{C}$ were incremented stepwise through a combination of $10^{-15}$ to $\ldots .10^{3}$ for $\mathrm{g}$, and $10^{-5}$ to. . $10^{15}$ for C. Svm_light was provided with these parameters along with the input training set and by varying these parameter values total 588 models are generated.

Subsequently each model was input to svm_classify to classify the test set sequences. The test set is a file containing positively and negatively labeled samples labeled 0 mixed in alternating order. The 3945 features of these samples were classified and the result is a numerical value for every sample. This numerical value above set threshold value of 0.0 is indicative of the sequence being classified as positive label or negative. This prediction is compared to our known knowledge of test set and performance of the model is evaluated.

\section{Threefold Cross Validation}

In order to obtain good performing models, threefold cross validation was done. Both positive and negative datasets were randomized 1000 times and divided into three parts, each having nearly equal number of proteins. The positive and negative subsets were merged to obtain three subsets. Then training and testing is conducted three times, each time using two subsets for training and the remaining third set for testing. Thus, each time, the testing is done on those proteins that are not a part of the training set (Figure 1). The assessment results of each test was carried out by computing the Mathews Correlation Coefficient (MCC values) [44] for each set of parameters, averaged over the three test sets and ranked in descending order of average MCC.

\section{Performance evaluation}

To evaluate the performance of the algorithm, specificity $(\mathrm{SP})$, sensitivity $(\mathrm{SN})$, accuracy $(\mathrm{ACC})$ and $\mathrm{MCC}$ were computed as per the following formulas:

$$
\begin{aligned}
& \mathrm{SP}=\mathrm{TP} /(\mathrm{TP}+\mathrm{FP}) \\
& \mathrm{SN}=\mathrm{TP} /(\mathrm{TP}+\mathrm{FN})
\end{aligned}
$$

Accuracy given by

$$
\frac{\mathrm{TP}+\mathrm{TN}}{\mathrm{TP}+\mathrm{TN}+\mathrm{FP}+\mathrm{FN}}
$$

MCC given by

$$
\frac{(\mathrm{TP} * \mathrm{TN})-(\mathrm{FP} * \mathrm{FN})}{\sqrt{ }(\mathrm{TN}+\mathrm{FN})(\mathrm{TN}+\mathrm{FP})(\mathrm{TP}+\mathrm{FN})(\mathrm{TP}+\mathrm{FP})}
$$

where TP is true positives; TN is true negatives; FP is false positives; FN is false negatives.

All evaluations were carried out at a base cutoff value of 0.0 as discriminator between positive and negative samples. This entire process was automated using perl scripts. Subsequently, coefficient of variation (CV) of MCC of each model across the three subsets was also calculated. In the next step, the models were arranged in descending order of MCC in each of the three subsets and the models with high average MCC value [0.831-0.919 (maximum)] and low CV ( $\leq 5 \%)$ were shortlisted.

\section{Performance Check on Human pathogenic fungal species}

The performance of each of these shortlisted models was evaluated on the entire proteomes of the eight fungal pathogens by testing their ability to identify known adhesins. We finally selected the best three models for the "Fungal RV adhesin predictor". These models along with the parameters are listed in Table 2. The final score is defined as $\mathrm{F}_{\text {prediction }}$ given by $\max$ \{score $\left(\mathrm{F}_{470 \mathrm{a}}\right)$ Uscore $\left.\left(\mathrm{F}_{470 \mathrm{~b}}\right) \cup \operatorname{score}\left(\mathrm{F}_{449 \mathrm{c}}\right)\right\}$ where max means maximum value in the expression. This produced minimal false positives. 


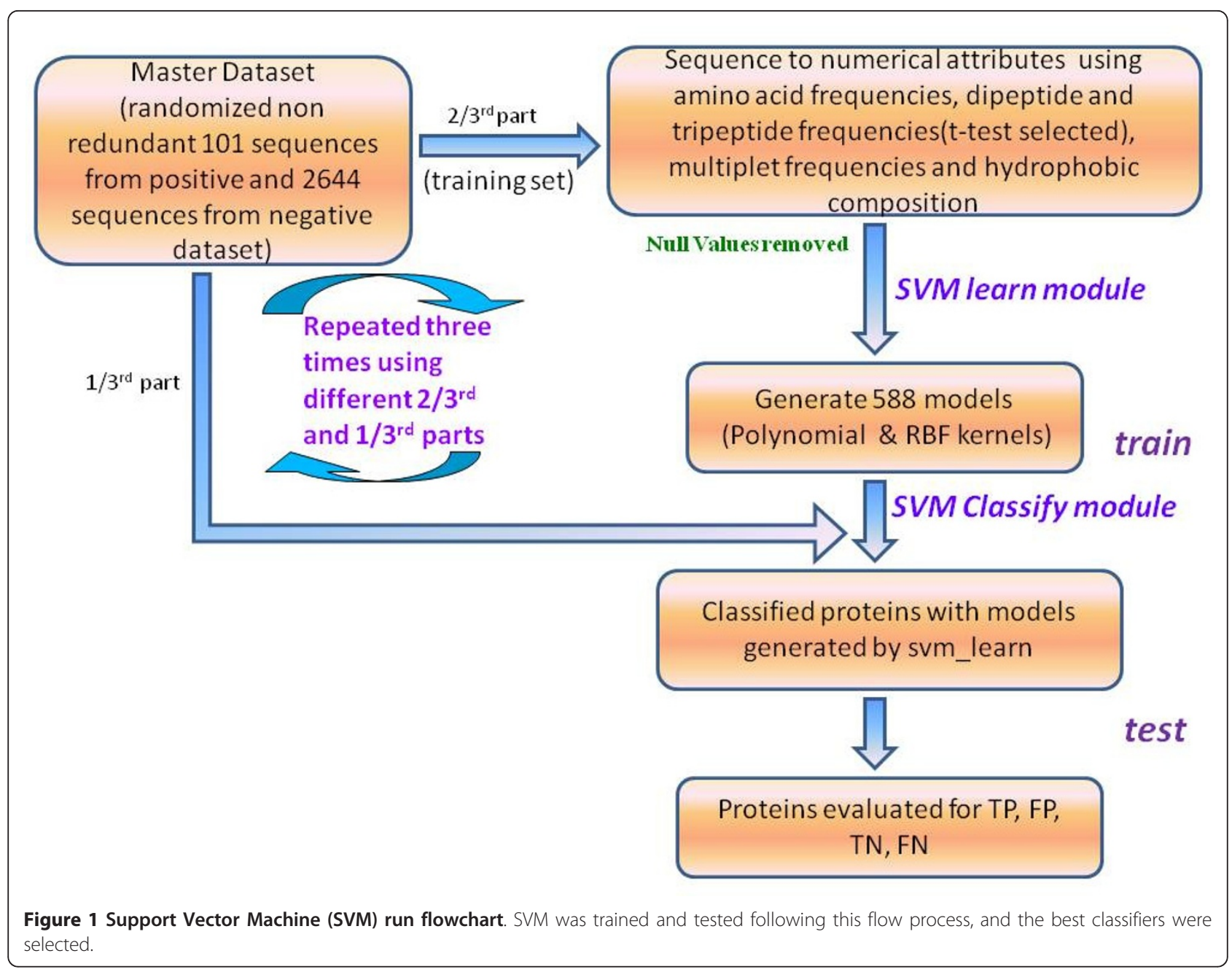

\section{Receiver operating characteristic Curve}

The Receiver operating characteristic Curve (ROC curve) was made from the result of "FungalRV adhesin predictor" run on the proteomes of eight human fungal pathogens. Proteins above the default threshold score of 0.0 were examined. Known adhesins were marked as true positives while proteins with probability to function intracellularly were marked false positives. The $\mathrm{R}$ software package ROCR was used to make the ROC curve
[45]. The best threshold inferred from the ROC curve is 0.873 . However we observed that this is too stringent and may miss prediction of many adhesins. Therefore the next point in ROC curve at threshold value of 0.511 was selected. Using this threshold, the algorithm is able to achieve a sensitivity of $100 \%$ for all human pathogens except in P. brasiliensis wherein a sensitivity of $66.67 \%$ was achieved. The overall MCC value of 0.8702 was achieved considering all 8 pathogens (Figure 2, Table 3).

Table 2 Parameter Sets and Performances of three Selected Models to Identify Fungal Adhesins and Adhesin-Like Proteins in human pathogenic fungal species

\begin{tabular}{|c|c|c|c|c|c|c|}
\hline $\begin{array}{l}\text { Best } \\
\text { model(classifier) } \\
\text { selected }\end{array}$ & $\begin{array}{l}\text { Kernel } \\
\text { Type }\end{array}$ & Parameters & $\begin{array}{l}\text { Performance of best } \\
\text { model (MCC) in the } \\
\text { selected subset }\end{array}$ & $\begin{array}{l}\text { Mean MCC for } \\
\text { parameters accoss } \\
\text { three subsets }\end{array}$ & $\begin{array}{l}\text { CV for parameters } \\
\text { accross three } \\
\text { subsets }\end{array}$ & Accuracy \\
\hline $470 a$ & $\mathrm{RBF}$ & $\begin{array}{l}g=0.01 \\
C=100\end{array}$ & 0.9189 & 0.8981 & $2.74 \%$ & $99.45 \%$ \\
\hline $470 b$ & RBF & $\begin{array}{l}g=0.01 \\
C=100\end{array}$ & 0.9044 & 0.8981 & $2.74 \%$ & $99.34 \%$ \\
\hline $449 c$ & $\mathrm{RBF}$ & $\begin{array}{l}g=0.001 \\
C=100\end{array}$ & 0.8876 & 0.8922 & $1.20 \%$ & $99.23 \%$ \\
\hline
\end{tabular}




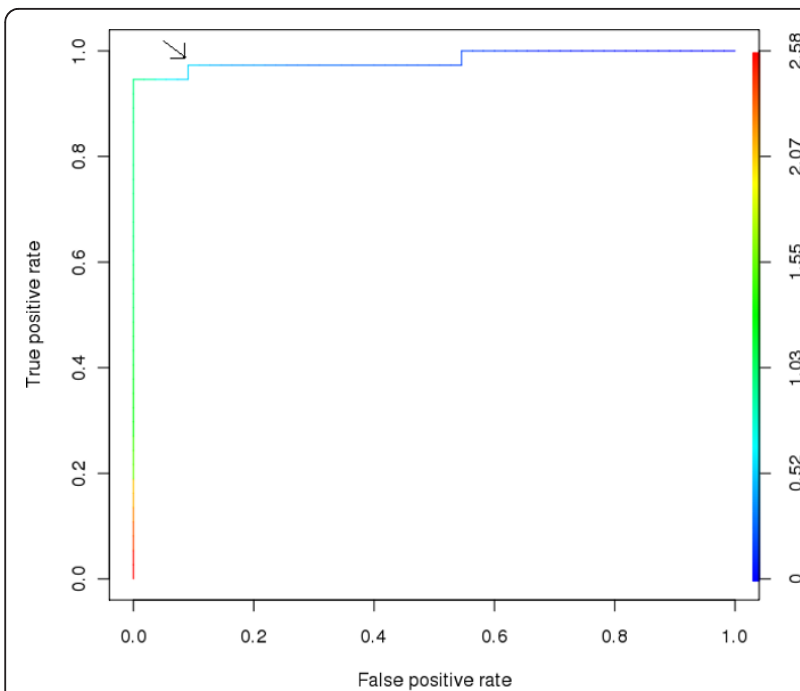

Figure $\mathbf{2}$ Receiver operating characteristic curve. The selected optimal threshold value (marked by arrow) for "FungalRV adhesin predictor" is shown.

\section{Performance Check on other fungal species}

Though our server focuses on human fungal pathogens adhesin prediction, we also checked its performance on a test set of fungal species not pathogenic for human. This test set of proteins was prepared from the SwissProt and the NCBI database by using search keywords "fungi" and "adhesin", "flocculin", "agglutinin". After removing the sequences corresponding to the human fungal pathogens we obtained 74 sequences from Pichia spp, Debaryomyces spp, Saccharomyces spp, Lachancea spp, Schizosaccharomyces spp, Kluyveromyces spp, Zygosaccharomyces spp, Neosartorya spp, Talaromyces spp, Botryotinia spp, Nectria spp, Metarhizium spp, Verticillium spp, Emericella spp, Vanderwaltozyma spp, Beauveria spp, Trichoderma spp, and Magnaporthe spp. In this case, a different combination of models of high MCC and low coefficient of variation appear appropriate in identifying 61 of 74 adhesins and thus giving a high sensitivity of $82.43 \%$. The $\mathrm{F}_{\text {prediction }}$ for this case is given by $\max \left\{\operatorname{score}\left(\mathrm{F}_{26 \mathrm{a}}\right) \operatorname{score}\left(\mathrm{F}_{470 \mathrm{~b}}\right) \operatorname{score}\left(\mathrm{F}_{6 \mathrm{c}}\right)\right\}$ where max means maximum value in the expression. These models along with their parameters are listed in Table 4.

\section{Immunoinformatics Data \\ Database architecture}

Protein sequences of known fungal vaccine candidates and of 307 predicted adhesins and adhesin like proteins were analyzed with 18 immunoinformatics algorithms displayed in Table 5. The ORF identification tags (ORF ID) assigned to proteins of fungal pathogens as given in the respected database repositories mentioned earlier were used as primary keys.

\section{Web Interface}

The Webserver is built on Apache version 2.0. Server side scripting was done in PHP version 5.1.4. The programs running at back-end for compositional property calculation are written in $\mathrm{C}$ programming language. These $C$ programs were compiled using the GNU gcc compiler 3.4.3 in the Itanium 2, 64-bit dual processor server running on Red Hat Linux Enterprise version 4. The client side scripting was prepared in HTML and AJAX. FungalRV can be best viewed with Mozilla Firefox and Internet Explorer. The database was developed using MySQL version 4.1.20 at back end and runs in Red Hat Enterprise Linux ES release 4. The database web interfaces have been developed in HTML and PHP 5.1.4, which dynamically execute the MySQL queries to fetch the stored data and is run through Apache2 server.

FungalRV web server has these tabs- "Adhesin Predictor", "Immunoinformatics Data", "Known Vaccines", "Download" and "Help". The "Adhesin Predictor" tab provides an interface where the users can paste or upload their query sequences and predict whether the protein sequence is a fungal adhesin (Figure 3). Users have the facility to set their own desired threshold cutoff value. The result can be exported as tab delimited text file by the users. The facility to search for fungal specific GPI pattern in the predicted adhesins and adhesin like proteins using fuzzpro program of EMBOSS has been

Table 3 Summary of predictions by FungalRV adhesin predictor using optimal threshold of 0.511

\begin{tabular}{llllll}
\hline Species & $\begin{array}{l}\text { Number of Proteins } \\
\text { above threshold }\end{array}$ & $\begin{array}{l}\text { Number of Known } \\
\text { Adhesins in proteome }\end{array}$ & $\begin{array}{l}\text { Number of adhesins } \\
\text { identified (Sensitivity) }\end{array}$ & $\begin{array}{l}\text { Number of hypothetical } \\
\text { Proteins }\end{array}$ & $\begin{array}{l}\text { Number of false } \\
\text { positives }\end{array}$ \\
\hline A. fumigatus & 38 & 2 & $2(100 \%)$ & 20 & 0 \\
\hline C. albicans & 81 & 14 & $14(100 \%)$ & 0 & 1 \\
\hline C. glabrata & 62 & 20 & $20(100 \%)$ & 0 & 2 \\
\hline B. dermatitidis & 33 & 1 & $1(100 \%)$ & 10 & 0 \\
\hline C. .mmitis & 23 & 1 & $1(100 \%)$ & 8 & 1 \\
\hline C. posadasii & 27 & 1 & $1(100 \%)$ & 13 & 1 \\
\hline H. capsulatum & 21 & 1 & $1(100 \%)$ & 6 & 0 \\
\hline P. brasiliensis & 27 & 3 & $2(66.67 \%)$ & 11 & \\
\hline
\end{tabular}


Table 4 Parameter Sets and Performances of three Selected Models to Identify Fungal Adhesins and Adhesin-Like Proteins in other fungi (not pathogenic to human)

\begin{tabular}{llllll}
\hline $\begin{array}{l}\text { Best model(classifier) } \\
\text { selected }\end{array}$ & Kernel Type & Parameters & $\begin{array}{l}\text { Performance of best model (MCC) } \\
\text { in the selected subset }\end{array}$ & $\begin{array}{l}\text { Mean MCC for parameters } \\
\text { accoss three subsets }\end{array}$ & $\begin{array}{l}\text { CV for parameters } \\
\text { accross three subsets }\end{array}$ \\
\hline $26 a$ & polynomial & $\begin{array}{l}d=2 \\
c=0.1\end{array}$ & 0.9019 & 0.89 & $3.24 \%$ \\
\hline $470 \mathrm{~b}$ & RBF & $\begin{array}{l}\mathrm{g}=0.01 \\
\mathrm{c}=100\end{array}$ & 0.9044 & 0.8981 & $2.74 \%$ \\
\hline $6 \mathrm{c}$ & polynomial & $\begin{array}{l}\mathrm{d}=1 \\
\mathrm{c}=1\end{array}$ & 0.9044 & 0.8945 & $0.9 \%$ \\
\hline
\end{tabular}

Table 5 Algorithms used to analyse predicted adhesins for Immunoinformatics

\begin{tabular}{|c|c|c|}
\hline Algorithm & Principle & Reference \\
\hline 1. BLASTCLUST & $\begin{array}{l}\text { Clusters protein or DNA sequences based on pairwise matches found using the BLAST algorithm } \\
\text { in case of proteins or Mega BLAST algorithm for DNA. }\end{array}$ & {$[60]$} \\
\hline 2. OrthoMCL & $\begin{array}{l}\text { OrthoMCL software was used to cluster proteins based on sequence similarity, using an all- } \\
\text { against-all BLAST search of each species' proteome, followed by normalization of inter-species } \\
\text { differences, and Markov clustering. }\end{array}$ & {$[61]$} \\
\hline 3. BetaWrap & $\begin{array}{l}\text { Predicts the right-handed parallel beta-helix supersecondary structural motif in primary amino } \\
\text { acid sequences by using beta-strand interactions learned from non-beta-helix structures. }\end{array}$ & {$[62]$} \\
\hline 4. Antigenic & $\begin{array}{l}\text { Predicts potentially antigenic regions of a protein sequence, based on occurrence frequencies of } \\
\text { amino acid residue types in known epitopes. }\end{array}$ & {$[63]$} \\
\hline 5. TargetP1.1 & $\begin{array}{l}\text { Predicts the subcellular location of eukaryotic proteins based on the predicted presence of any } \\
\text { of the N-terminal presequences: chloroplast transit peptide (cTP), mitochondrial targeting } \\
\text { peptide (mTP) or secretory pathway signal peptide (SP). }\end{array}$ & {$[64]$} \\
\hline 5. SignalP 3.0 & $\begin{array}{l}\text { Predicts the presence and location of signal peptide cleavage sites in amino acid sequences } \\
\text { from different organisms. The method incorporates a prediction of cleavage sites and a signal } \\
\text { peptide/non-signal peptide prediction based on a combination of several artificial neural } \\
\text { networks and hidden Markov models. }\end{array}$ & {$[65]$} \\
\hline 6. TMHMM Server v. 2.0 & Predicts the transmembrane helices in proteins based on Hidden Markov Model. & {$[66]$} \\
\hline $\begin{array}{l}\text { 7. Conserved Domain Database and } \\
\text { Search Service, } v 2.22\end{array}$ & $\begin{array}{l}\text { The Database is a collection of multiple sequence alignments for ancient domains and full- } \\
\text { length proteins. It is used to identify the conserved domains present in a protein query } \\
\text { sequence. }\end{array}$ & {$[67]$} \\
\hline 8. BlastP & $\begin{array}{l}\text { It uses the BLAST algorithm to compare an amino acid query sequence against a protein } \\
\text { sequence database. }\end{array}$ & {$[68]$} \\
\hline 9. ABCPred & Predict B cell epitope(s) in an antigen sequence, using artificial neural network. & {$[69]$} \\
\hline 10. BcePred & Predicts linear B-cell epitopes, using physico-chemical properties. & {$[70]$} \\
\hline 11. Discotope 1.2 & $\begin{array}{l}\text { Predicts discontinuous B cell epitopes from protein three dimensional structures utilizing } \\
\text { calculation of surface accessibility (estimated in terms of contact numbers) and a novel epitope } \\
\text { propensity amino acid score. }\end{array}$ & {$[71]$} \\
\hline 12. BEPro & $\begin{array}{l}\text { BEPro, uses a combination of amino-acid propensity scores and half sphere exposure values at } \\
\text { multiple distances to achieve state-of-the-art performance. }\end{array}$ & {$[72]$} \\
\hline 13. Propred & $\begin{array}{l}\text { Predicts MHC Class-II binding regions in an antigen sequence, using quantitative matrices } \\
\text { derived from published literature. It assists in locating promiscous binding regions that are useful } \\
\text { in selecting vaccine candidates. }\end{array}$ & {$[73]$} \\
\hline $\begin{array}{l}\text { 14. IEDB-AR (Average Relative Binding } \\
\text { Method) }\end{array}$ & $\begin{array}{l}\text { Predicts IC(50) values allowing combination of searches involving different peptide sizes and } \\
\text { alleles into a single global prediction. }\end{array}$ & {$[74,75]$} \\
\hline 15. Bimas & $\begin{array}{l}\text { Ranks potential 8-mer, 9-mer, or 10-mer peptides based on a predicted half-time of dissociation } \\
\text { to HLA class I molecules. The analysis is based on coefficient tables deduced from the published } \\
\text { literature by Dr. Kenneth Parker, Children's Hospital Boston. }\end{array}$ & {$[76]$} \\
\hline 16. NetMHC 3.0 & $\begin{array}{l}\text { Predicts binding of peptides to a number of different HLA alleles using artificial neural networks } \\
\text { (ANNs) and weight matrices. }\end{array}$ & {$[77]$} \\
\hline 17. AlgPred & $\begin{array}{l}\text { Predicts allergens in query protein based on similarity to known epitopes, searching MEME/MAST } \\
\text { allergen motifs using MAST and assign a protein allergen if it have any motif, search based on } \\
\text { SVM modules and search with BLAST search against } 2890 \text { allergen-representative peptides } \\
\text { obtained from Bjorklund et al } 2005 \text { and assign a protein allergen if it has a BLAST hit. }\end{array}$ & {$[78]$} \\
\hline 18. Allermatch & $\begin{array}{l}\text { Predicts the potential allergenicity of proteins by bioinformatics approaches as recommended by } \\
\text { the Codex alimentarius and FAOMHO Expert consultation on allergenicity of foods derived } \\
\text { through modern biotechnology. }\end{array}$ & [79] \\
\hline
\end{tabular}


FungalRV adhesin predictor is designed to predict Human Pathogenic Fungal adhesins and adhesins-like proteins. It is based on Support Vector Machines. It accepts protein sequences in FASTA format and produces a score, which above the threshold value is an indication of probability of a pathogenic fungal protein having an adhesin or adhesin-like features.

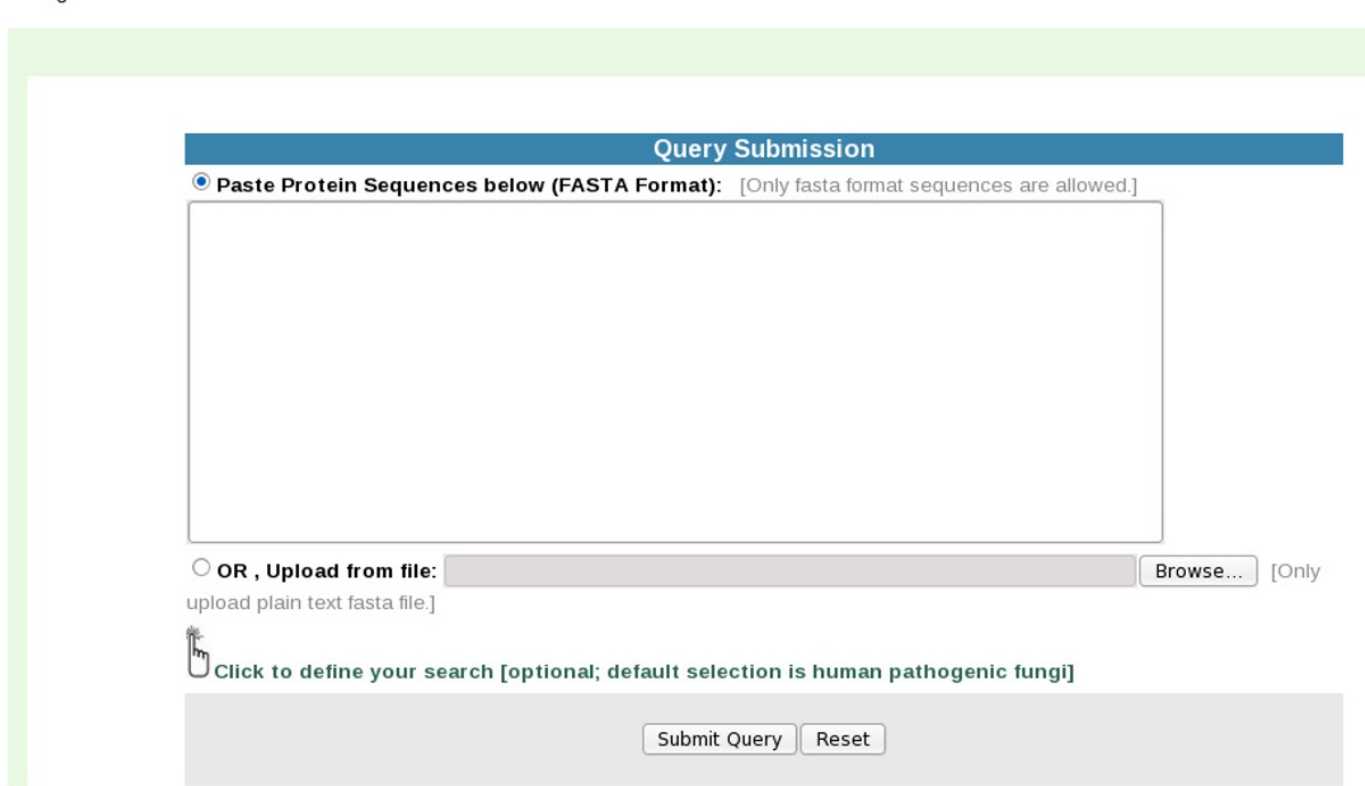

Figure 3 FungalRV adhesin predictor Web site. Users can paste or upload sequences in FASTA format for human pathogenic fungal adhesin and adhesin-like proteins prediction.

provided [46,47]. Users also have been provided the facility to conduct BLAST search with human reference proteins.

On clicking the "Immunoinformatics Data" tab, users are directed to the FungalRV database of predicted fungal adhesins and adhesin like proteins (Figure 4). Here users can search the database for adhesin proteins and their attributes corresponding to one or more ORF identification tags of a species or against a specific keyword. Advanced search facility of predicted fungal adhesins is also provided where the results can be filtered on the basis of protein length, number of transmembrane spanning regions, localization and reliability class, presence or absence of betawraps, paralogs, hits to Conserved Domain Database and Human Reference proteins (retrieved from NCBI through ftp on 7 August, 2010). The results obtained can be exported by the user as a text file in both processes.

The "Known Vaccines" tab takes user to the page containing the list of known vaccine candidates provided in tabular form.

\section{Utility and Discussion}

Adhesin prediction for human fungal pathogens User interface -

A user friendly interface was developed for using the "Fungal RV adhesin predictor" algorithm. Users can paste the sequence in FASTA format or even upload a file. A threshold of 0.511 was set as the optimal threshold (Figure 2). However, users can set a threshold of their own choice. The results are displayed in a colour coded tabular format. 'See additional file 2: Adhesins and adhesin like proteins predicted by "FungalRV adhesin predictor" in 8 human fungal pathogens'. Results can be exported in tab delimited text format.

Our algorithm "FungalRV adhesin predictor" predicted many cell surface GPI anchored proteins as novel adhesins from the 8 fungal pathogens. 'See additional file 3: GPI anchored proteins predicted as adhesin by FungalRV adhesin Predictor'. GPI anchor proteins in fungi are known to be either covalently incorporated into the cell wall network or remain attached to the plasma membrane. The predicted amino acid sequences of GPI 


\section{FungalRV}

An Adhesin Prediction and Immunoinformatics portal for human fungal pathogens

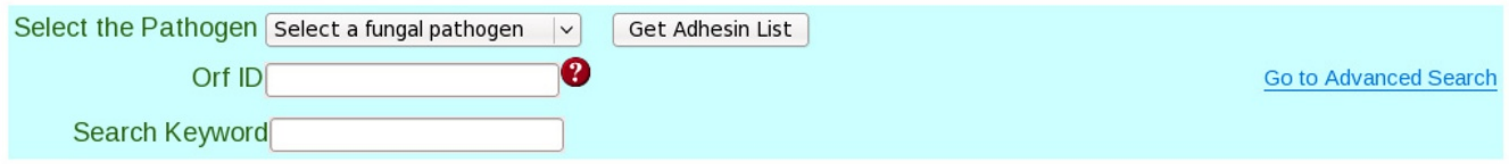

Data Available

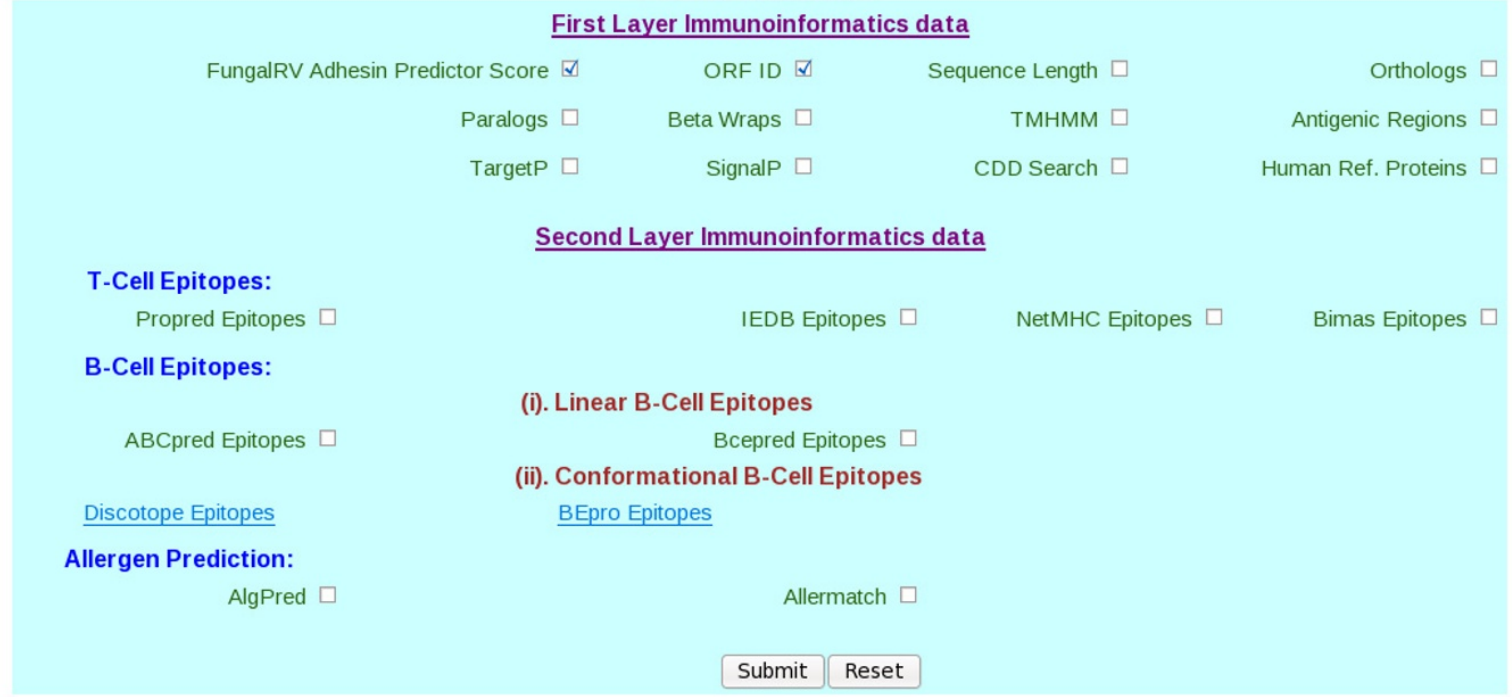

Figure 4 FungalRV Immunoinformatics Web site. Users can query FungalRV Immunoinformatics database for data useful from reverse vaccinology point of view corresponding to the predicted 307 adhesin and adhesin like proteins and known vaccine candidates.

proteins conform to a general pattern. Their N-termini has a hydrophobic signal sequence that directs the protein to the ER and their C-termini has a second hydrophobic domain, which is cleaved off and replaced with a GPI anchor (a preformed lipid in the membrane of the endoplasmic reticulum) by a transamidase enzyme complex. The GPI anchored proteins are linked to plasma membrane via this preformed GPI anchor [48]. These proteins may have roles in cell wall biosynthesis, cell wall remodeling, determining surface hydrophobicity and antigenicity and in adhesion and virulence $[49,50]$.

In C. albicans "FungalRV adhesin predictor" predicted proteins proposed to be involved in the process of adhesion to host such as SUN41, IFF4 [51,52]. These proteins were not included in the training set due to absence of evidence on their direct involvement in adhesion process. However, their eventual prediction as adhesins by "FungalRV adhesin predictor" suggests their potential role in mediating adhesion. "FungalRV adhesin predictor" at optimal threshold of 0.511 predicts all the members of ALS and Hyr/iff (GPI family 17 and 18), proposed to be involved in modulating adhesion and biofilm formation in C. albicans [26]. The ALS family in $C$. albicans is characterized as the main class of adhesins $[53,54]$. Another protein RBT1 showing similarity to HWP1 and may have adhesion property [55] is also predicted by "FungalRV adhesin predictor".

In C. glabrata, several proteins showing similarity to flocculins and STA1 glucoamylase homologue of S. cerevisiae were predicted. 'See additional file 4: Predicted adhesins from C. glabrata with similarity to either flocculins or STA1'. The flocculins are involved in adhesion process in S. cerevisiae [56,57] and therefore it is probable that these proteins have functional similarity in their role as adhesins in C. glabrata as well. When compared to the predicted in-silico adhesins by Weig et al [25], the new release of C. glabrata proteome by Genolevures (Sep. 2009) retains 28 orfids of the 51 orfids predicted as adhesins in the older proteome release by Genolevures (June 2004). "FungalRV adhesin predictor" could predict 24 of the 28 in-silico predicted adhesins at optimal threshold value of 0.511 . 'See additional file 5 : 
"FungalRV adhesin predictor" scores of In-silico predicted adhesins by Weig et al'.

ClustalW [58] analysis among the 307 predicted adhesin and adhesin like proteins obtained from "FungalRV adhesin predictor" run on entire proteomes of eight human pathogenic fungal species showed that most (99.65\%) of the predicted adhesin sequence pairs have ClustalW score in the range of 0-35\% (Figure 5). These data show that "FungalRV adhesin predictor" could predict adhesin sequences from diverse fungal pathogens thereby attesting its non-homology characteristic.

"FungalRV adhesin predictor" run on proteomes of some of the human pathogenic fungi with low incidence of occurrence-Candida dubliniensis, Candida tropicalis, Candida parapsilosis, Candida lusitaniae and Candida guilliermondii has been provided as supplementary data. 'See additional file 6: Adhesins and adhesin like proteins predicted by "FungalRV adhesin predictor" in other pathogenic fungi with low occurrence of incidence'.

Our algorithm FungalRV adhesin predictor uses highly accurate SVM models (greater than 99\%) and therefore it achieves a good MCC of 0.8702 at a positive threshold of 0.511 in comparison to FAAPred [59], which uses SVM models of lower accuracy (86\%) and achieves a MCC of 0.610 at a relatively high negative threshold of -0.8 . FAAPred misses identifying integrins (a class of known adhesins) from C. albicans and P. carinii and in some cases identifies known adhesins with low score in the range $(-0.06$ to -0.74$)$ indicating low confidence predictions in contrast to our algorithm.

\section{Immunoinformatics Database}

The FungalRV immunoinformatics database houses immunoinformatics data on 307 predicted adhesins and adhesin like proteins obtained by "FungalRV adhesin predictor" run on entire proteomes of eight human pathogenic fungal species. This includes 80 from $C$. albicans, 62 from C. glabrata, 38 from A. fumigatus, 31 from $B$. dermatitidis, 27 from $P$. brasiliensis, 20 from $H$. capsulatum, 23 from C. immitis and 26 from C. posadasii. The database houses detailed information on proteins analysed through 18 algorithms important from the view of reverse vaccinology (Table 5) [60-79]. The analysis through these algorithms provide a broad range of information regarding Orthologs, Paralogs, BetaWraps, Localization, Transmembrane spanning regions,

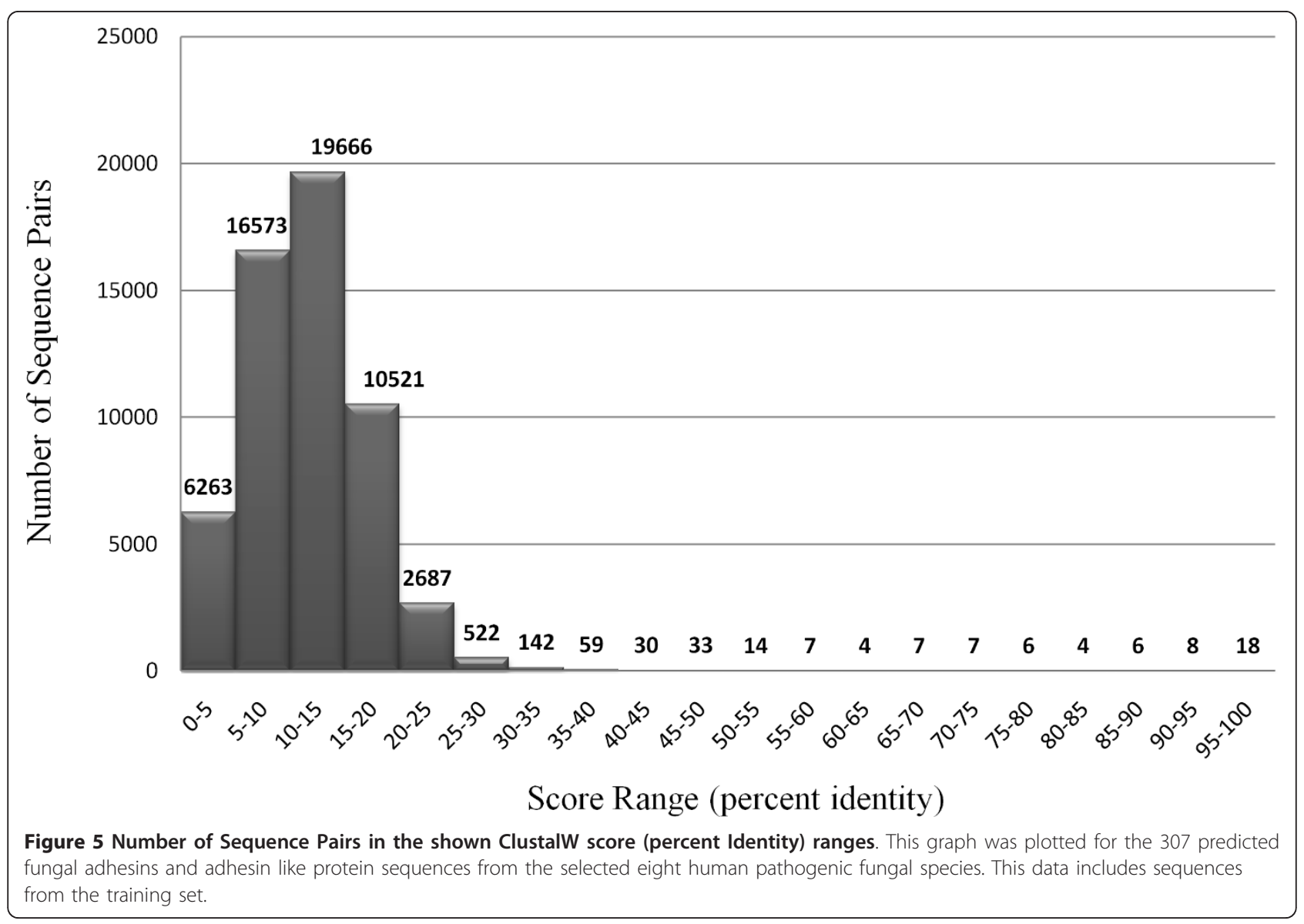




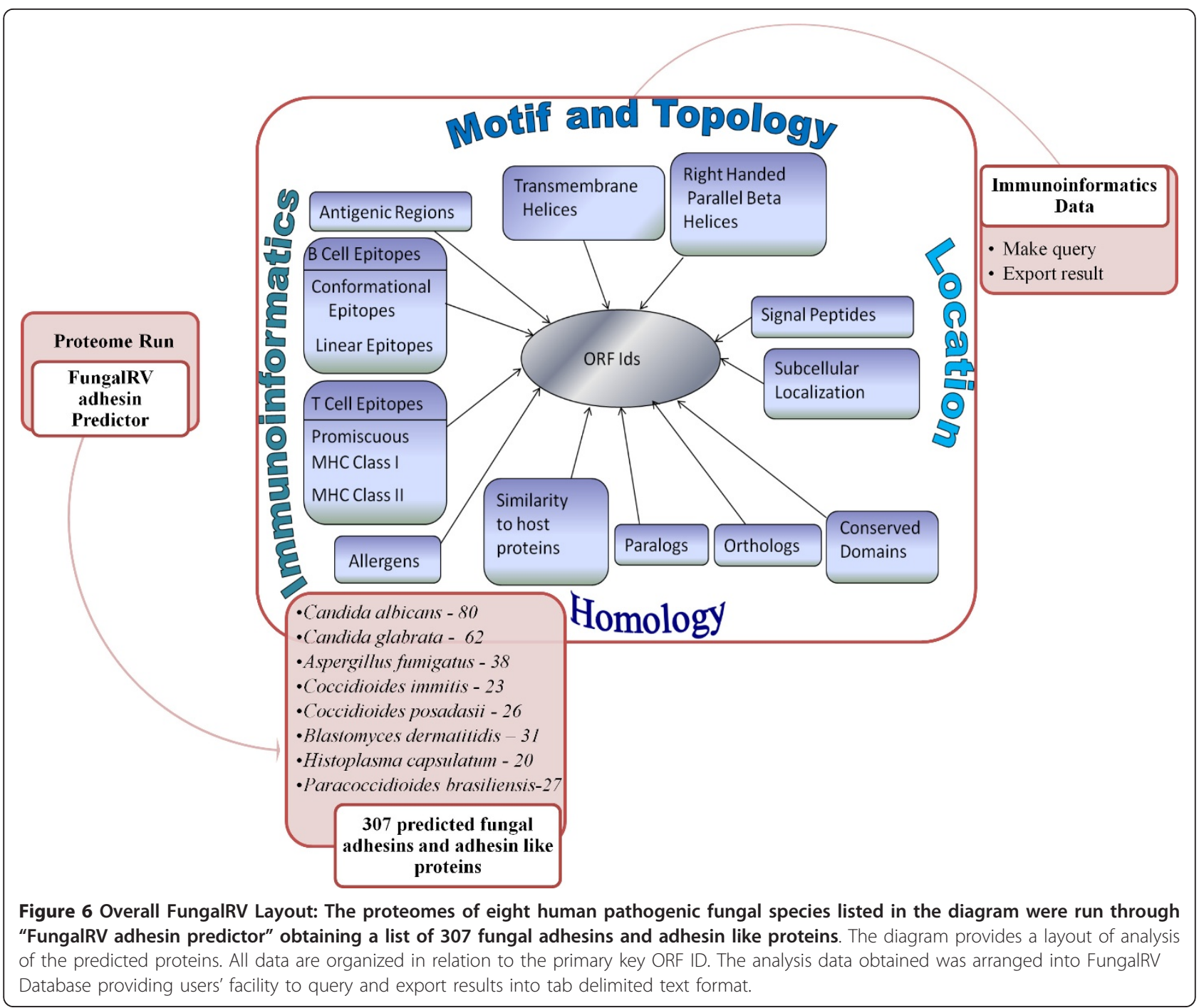

Signal Peptides, Conserved domains, similarity to Human Reference Proteins, T-cell epitopes, B-cell epitopes, Discotopes, and Allergen predictions. The overall layout of FungalRV is provided in Figure 6

First level of searching and retrieval of data is possible either through ORF ID or keywords. Multiple ORF IDs can be submitted using comma separation. Keywords can be used singly. If multiple keywords are used then the search is implemented using the AND Boolean. In the case of searching for epitope data, due to their huge size, data are conveniently retrieved in a singular mode for each ORF ID specifically. All data can be exported conveniently as a text file.

\section{Conclusion}

A Web server aiding in novel human pathogenic fungal adhesin vaccine prediction and development has been prepared [80].

\section{Availability and Requirement}

Sever can be accessed at http://fungalrv.igib.res.in. The server is best viewed with Explorer 8.0 or later and Mozilla firefox version 3.0 or later

\section{Additional material}

Additional file 1: Pfam Domain Search Result of negative dataset.

Additional file 2: Adhesins and adhesin like proteins predicted by FungalRV adhesin Predictor in $\mathbf{8}$ human fungal pathogens. The file lists 307 adhesins and adhesin like proteins obtained by "FungalRV adhesin predictor" run on entire proteomes of eight human pathogenic fungal species along with their FungalRV adhesin predictor scores. Known adhesins are coloured in Green.

Additional file 3: GPI anchored proteins predicted as adhesin by FungalRV adhesin predictor. FungalRV adhesin predictor predicted many cell surface GPI anchored proteins as novel adhesins. These proteins along with their FungalRV adhesin predictor score are listed in this file. 
Additional file 4: Predicted adhesins from Candida glabrata with similarity to either flocculins or STA1. Predicted adhesins from Candida glabrata with similarity to either flocculins or STA1 by "FungalRV adhesin predictor" along with their "FungalRV adhesin predictor" scores are listed in this file.

Additional file 5: "FungalRV adhesin predictor" scores of In-silico predicted adhesins by Weig et al. "FungalRV adhesin predictor" scores of In-silico predicted adhesins by Weig et al. are listed in this file.

Additional file 6: Adhesins and adhesin like proteins predicted by "FungalRV adhesin predictor" in other pathogenic fungi with low incidence of occurrence. The file lists adhesins and adhesin like proteins obtained by "FungalRV adhesin predictor" run on entire proteomes of some of the human pathogenic fungi with low incidence of occurrence along with their FungalRV adhesin predictor scores.

\section{Acknowledgements and Funding}

This work was supported in part by grants to SR "Integrated in silico analysis of Surface proteins from selected Microbial Pathogens: Identification, structure modeling, scanning for active \& binding sites, docking analysis of ligands and small molecules", from the Department of Science and Technology, Govt. of India, and a fellowship from The Indian Council of Medical Research. We thank Shri Vijay Kumar Nalla, for discussions.

\section{Authors' contributions}

SR conceived the idea and provided guidance, suggestions, critical comments, and testing of FungalRV. RC prepared the positive and negative datasets and performed training to generate model classifiers. RC carried out testing, selection of the best models. RC collected immunoinformatics data, organized systematically, prepared the codes for FungalRV. FAA provided help with preparing the codes. MVR helped in system set up, maintenance and administration. SR and RC wrote the manuscript. All authors have read and approved the final manuscript.

\section{Authors' information}

SR is a Bioinformatics scientist with focus on infectious diseases at the Institute of Genomics and Integrative Biology (CSIR), Delhi 110 007, India. RC is a Ph.D. student carrying out her thesis work at the Institute of Genomics and Integrative Biology (CSIR), Delhi 110 007, India. MVR is a systems scientist at the Institute of Genomics and Integrative Biology (CSIR), Delhi 110 007, India

\section{Competing interests}

The authors declare that they have no competing interests.

Received: 21 September 2010 Accepted: 15 April 2011 Published: 15 April 2011

\section{References}

1. Pfaller MA, Diekema DJ: Epidemiology of invasive candidiasis: a persistent public health problem. Clin Microbiol Rev 2007, 20:133-63.

2. Armstrong-James D: Invasive Candida species infection: the importance of adequate empirical antifungal therapy. J Antimicrob Chemother 2007, 60:459-460.

3. Vazquez JA, Sobel JD: Candidiasis. In Clinical Mycology. Edited by: Dismukes WE, Pappas PG, Sobel JD. Oxford Univers; 2003:143-187.

4. Dagenais TR, Keller NP: Pathogenesis of Aspergillus fumigatus in Invasive Aspergillosis. Clin Microbiol Rev 2009, 22:447-465.

5. Latgé JP: Aspergillus fumigatus and aspergillosis. Clin Microbiol Rev 1999, 12:310-350.

6. Saubolle MA, McKellar PP, Sussland D: Epidemiologic, clinical, and diagnostic aspects of coccidioidomycosis. J Clin Microbiol 2007, 45:26-30

7. Kauffman CA: Histoplasmosis. Clin Chest Med 2009, 30:217-225.

8. McKinnell JA, Pappas PG: Blastomycosis: new insights into diagnosis, prevention, and treatment. Clin Chest Med 2009, 30:227-239.

9. Deepe GS Jr, Wüthrich M, Klein BS: Progress in vaccination for histoplasmosis and blastomycosis: coping with cellular immunity. Med Mycol 2005, 43:381-389.
10. Grossklaus Dde A, Tadano T, Breder SA, Hahn RC: Acute disseminated paracoccidioidomycosis in a 3 year-old child. Braz J Infect Dis 2009, 13:242-344.

11. Thomas CF Jr, Limper AH: Current insights into the biology and pathogenesis of Pneumocystis pneumonia. Nat Rev Microbiol 2007, 5:298-308.

12. Cutler JE, Deepe GS Jr, Klein BS: Advances in combating fungal diseases: vaccines on the threshold. Nat Rev Microbiol 2007, 5:13-28.

13. Cassone A: Fungal vaccines: real progress from real challenges. Lancet Infect Dis 2008, 8:114-24.

14. Wizemann TM, Adamou JE, Langermann S: Adhesins as targets for vaccine development. Emerg Infect Dis 1999, 5:395-403.

15. Spellberg BJ, Ibrahim AS, Avenissian V, Filler SG, Myers CL, Fu Y, Edwards JE $\mathrm{Jr}$ : The anti-Candida albicans vaccine composed of the recombinant $\mathrm{N}$ terminus of Als $1 p$ reduces fungal burden and improves survival in both immunocompetent and immunocompromised mice. Infect Immun 2005, 73:6191-6193.

16. Ibrahim AS, Spellberg BJ, Avanesian V, Fu Y, Edwards JE Jr: The antiCandida vaccine based on the recombinant $\mathrm{N}$-terminal domain of Als $1 \mathrm{p}$ is broadly active against disseminated candidiasis. Infect Immun 2006, 74:3039-3041

17. Wüthrich M, Chang WL, Klein BS: Immunogenicity and protective efficacy of the WI-1 adhesin of Blastomyces dermatitidis. Infect Immun 1998, 66:5443-5449.

18. Wüthrich M, Filutowicz HI, Warner T, Klein BS: Requisite elements in vaccine immunity to Blastomyces dermatitidis: plasticity uncovers vaccine potential in immune-deficient hosts. J Immunol 2002, 169:6969-6976.

19. Braga CJ, Rittner GM, Muñoz Henao JE, Teixeira AF, Massis LM, SbrogioAlmeida ME, Taborda CP, Travassos LR, Ferreira LC: Paracoccidioides brasiliensis vaccine formulations based on the gp43-derived P10 sequence and the Salmonella enterica FliC flagellin. Infect Immun 2009, 77:1700-1707.

20. Pinto AR, Puccia R, Diniz SN, Franco MF, Travassos LR: DNA-based vaccination against murine paracoccidioidomycosis using the gp43 gene from paracoccidioides brasiliensis. Vaccine 2000, 18:3050-3058

21. Hung CY, Ampel NM, Christian L, Seshan KR, Cole GT: A major cell surface antigen of Coccidioides immitis which elicits both humoral and cellular immune responses. Infect Immun 2000, 68:584-93.

22. Hung CY, Yu JJ, Seshan KR, Reichard U, Cole GT: A parasitic phase-specific adhesin of Coccidioides immitis contributes to the virulence of this respiratory fungal pathogen. Infect Immun 2002, 70:3443-3456.

23. Verstrepen $\mathrm{K}$, Klis FM: Flocculation, adhesion and biofilm formation in yeasts. Mol Microbiol 2006, 60:5-15.

24. Dranginis AM, Rauceo JM, Coronado JE, Lipke PN: A biochemical guide to yeast adhesins: glycoproteins for social and antisocial occasions. Microbiol Mol Biol Rev 2007, 71:282-294.

25. Weig M, Jänsch L, Gross U, De Koster CG, Klis FM, De Groot PW: Systematic identification in silico of covalently bound cell wall proteins and analysis of protein-polysaccharide linkages of the human pathogen Candida glabrata. Microbiology 2004, 150:3129-3144.

26. Butler G, Rasmussen MD, Lin MF, Santos MA, Sakthikumar S, Munro CA, Rheinbay E, Grabherr M, Forche A, Reedy JL, Agrafioti I, Arnaud MB, Bates S, Brown AJ, Brunke S, Costanzo MC, Fitzpatrick DA, de Groot PW, Harris D, Hoyer LL, Hube B, Klis FM, Kodira C, Lennard N, Logue ME, Martin R, Neiman AM, Nikolaou E, Quail MA, Quinn J, Santos MC, Schmitzberger FF, Sherlock G, Shah P, Silverstein KA, Skrzypek MS, Soll D, Staggs R, Stansfield I, Stumpf MP, Sudbery PE, Srikantha T, Zeng Q, Berman J, Berriman M, Heitman J, Gow NA, Lorenz MC, Birren BW, Kellis M, Cuomo CA: Evolution of pathogenicity and sexual reproduction in eight Candida genomes. Nature 2009, 459:657-662.

27. Ansari FA, Kumar N, Bala Subramanyam M, Gnanamani M, Ramachandran S: MAAP: malarial adhesins and adhesin-like proteins predictor. Proteins 2008, 70:659-666.

28. Sachdeva G, Kumar K, Jain P, Ramachandran S: SPAAN: a software program for prediction of adhesins and adhesin-like proteins using neural networks. Bioinformatics 2005, 21:483-491.

29. Chaudhuri R, Ahmed S, Ansari FA, Singh HV, Ramachandran S: MalVac: database of malarial vaccine candidates. Malar J 2008, 7:184.

30. Takala SL, Coulibaly D, Thera MA, Batchelor AH, Cummings MP, Escalante AA, Ouattara A, Traoré K, Niangaly A, Djimdé AA, Doumbo OK, 
Plowe CV: Extreme polymorphism in a vaccine antigen and risk of clinical malaria: implications for vaccine development. Sci Trans/ Med 2009, 1:2ra5.

31. Rigden DJ, Mello LV, Galperin MY: The PA14 domain, a conserved all-beta domain in bacterial toxins, enzymes, adhesins and signaling molecules. Trends Biochem Sci 2004, 29:335-339.

32. Linder T, Gustafsson CM: Molecular phylogenetics of ascomycotal adhesins-a novel family of putative cell-surface adhesive proteins in fission yeasts. Fungal Genet Biol 2008, 45:485-497.

33. Cooper SPeter, Lipshultz Dawn, Matten TWayne, McGinnis DScott, Pechous Steven, Romiti LMonica, Tao Tao, Valjavec-Gratian Majda, Sayers WEric: Education resources of the National Center for Biotechnology Information. Briefings in Bioinformatics. 2010.

34. Arnaud MB, Costanzo MC, Skrzypek MS, Binkley G, Lane C, Miyasato SR, Sherlock G: The Candida Genome Database (CGD), a community resource for Candida albicans gene and protein information. Nucleic Acids Res 2005, , 33 Database: D358-63.

35. Schneider M, Tognolli M, Bairoch A: The Swiss-Prot protein knowledgebase and ExPASy: providing the plant community with high quality proteomic data and tools.Plant Physiol Biochem. Plant Physiol Biochem 2004, 42:1013-1021.

36. Sherman D, Durrens P, Beyne E, Nikolski M, Souciet JL: Génolevures Consortium: Génolevures: comparative genomics and molecular evolution of hemiascomycetous yeasts. Nucleic Acids Res 2004, 32 Database: D315-8.

37. Upadhyay SK, Mahajan L, Ramjee S, Singh Y, Basir SF, Madan T: Identification and characterization of a laminin-binding protein of Aspergillus fumigatus: extracellular thaumatin domain protein (AfCalAp). J Med Microbiol 2009, 58:714-722.

38. McCarthy AA: Broad institute: bringing genomics to real-world medicine. Chem Biol 2005, 12:717-718.

39. Brendel V, Bucher P, Nourbakhsh IR, Blaisdell BE, Karlin S: Methods and algorithms for statistical analysis of protein sequences. Proc Natl Acad Sci USA 1992, 89:2002-2006.

40. R: A language and environment for statistical computing. Vienna, Austria: R Foundation for Statistical Computing; 2006.

41. Kyte J, Doolittle R: A simple method for displaying the hydropathic character of a protein. J Mol Biol 1982, 157:105-132.

42. Vapnik VN: The nature of statistical learning theory. New York. SpringerVerlag; 1995.

43. Joachims T: Making large-scale SVM learning practical. In MA: MIT Press. Edited by: Scholkopf B, Burges C, Smola A. Advances in Kernel methodssupport vector learning. Cambridge; 1999:169-185.

44. Matthews BW: Comparison of the predicted and observed secondary structure of T4 phage lysozyme. Biochim Biophys Acta 1975, 405:442-451.

45. Sing T, Sander O, Beerenwinkel N, Lengauer T: ROCR: visualizing classifier performance in R. Bioinformatics 2005, 21:3940-3941.

46. De Groot PW, Hellingwerf KJ, Klis FM: Genome-wide identification of fungal GPI proteins. Yeast 2003, 20:781-796

47. Yan T, Yoo D, Berardini TZ, Mueller LA, Weems DC, Weng S, Cherry JM, Rhee SY: PatMatch: a program for finding patterns in peptide and nucleotide sequences. Nucleic Acids Res 2005, 33.

48. Tiede A, Bastisch I, Schubert J, Orlean P, Schmidt RE: Biosynthesis of glycosylphosphatidylinositols in mammals and unicellular microbes. Biol Chem 1999, 380:503-23.

49. De Groot PW, Hellingwerf KJ, Klis FM: Genome-wide identification of fungal GPI proteins. Yeast 2003, 20:781-796

50. Plaine A, Richard ML: Comprehensive Analysis of Glycosylphosphatidylinositol-Anchored Proteins in Candida albicans. Eukaryot Cell 2007, 6:119-133.

51. Hiller E, Heine S, Brunner H, Rupp S: Candida albicans Sun41p, a putative glycosidase, is involved in morphogenesis, cell wall biogenesis, and biofilm formation. Eukaryot Cell 2007, 6:2056-2065.

52. Kempf M, Cottin J, Licznar $P$, Lefrançois C, Robert $R$, Apaire-Marchais V: Disruption of the GPI protein-encoding gene IFF4 of Candida albicans results in decreased adherence and virulence. Mycopathologia 2009, 168:73-77.

53. Hoyer LL: The ALS gene family of Candida albicans. Trends Microbiol 2001, 9:176-180
54. Nobile CJ, Schneider HA, Nett JE, Sheppard DC, Filler SG, Andes DR, Mitchell AP: Complementary adhesin function in C. albicans biofilm formation. Curr Biol 2008, 18:1017-1024

55. Plaine A, Walker L, Da Costa G, Mora-Montes HM, McKinnon A, Gow NA Gaillardin C, Munro CA, Richard ML: Functional analysis of Candida albicans $\mathrm{GPI}$-anchored proteins: roles in cell wall integrity and caspofungin sensitivity. Fungal Genet Biol 2008, 45:1404-1414.

56. Lo WS, Dranginis AM: FLO11, a yeast gene related to the STA genes, encodes a novel cell surface flocculin. J Bacteriol 1996, 178:7144-51.

57. Douglas LM, Li L, Yang Y, Dranginis AM: Expression and characterization of the flocculin Flo11/Muc1, a Saccharomyces cerevisiae mannoprotein with homotypic properties of adhesion. Eukaryot Cell 2007, 6:2214-2221.

58. Larkin MA, Blackshields G, Brown NP, Chenna R, McGettigan PA, McWilliam H, Valentin F, Wallace IM, Wilm A, Lopez R, Thompson JD, Gibson TJ, Higgins DG: Clustal W and Clustal X version 2.0. Bioinformatics 2007, 23:2947-2948, Epub 2007 Sep 10.

59. Ramana J, Gupta D: FaaPred: a SVM-based prediction method for fungal adhesins and adhesin-like proteins. PLoS One 2010, 5:e9695.

60. Kondrashov FA, Rogozin IB, Wolf YI, Koonin EV: Selection in the evolution of gene duplications. Genome Biol 2002, 3:RESEARCH0008.

61. Chen F, Mackey AJ, Stoeckert CJ Jr, Roos DS: OrthoMCL-DB: querying a comprehensive multi-species collection of ortholog groups. Nucleic Acid Res 2006, D363-368.

62. Bradley P, Cowen L, Menke M, King J, Berger B: BETAWRAP: successful prediction of parallel beta-helices from primarysequence reveals an association with many microbial pathogens. Proc Natl Acad Sci USA 2001, 98:14819-14824.

63. Kolaskar AS, Tongaonkar PC: A semi-empirical method for prediction of antigenic determinants on protein antigens. FEBS Lett 1990, 276:172-174.

64. Emanuelsson O, Nielsen $\mathrm{H}$, Brunak S, von Heijne G: Predicting subcellular localization of proteins based on their $\mathrm{N}$-terminal amino acid sequence. J Mol Biol 2000, 300:1005-1016.

65. Bendtsen JD, Nielsen $H$, von Heijne G, Brunak S: Improved prediction of signal peptides: SignalP 3.0. J Mol Biol 2004, 340:783-795.

66. Krogh A, Larsson B, von Heijne G, Sonnhammer EL: Predicting transmembrane protein topology with a hidden Markov model: application to complete genomes. J Mol Biol 2001, 305:567-580.

67. Marchler-Bauer A, Anderson JB, Cherukuri PF, DeWeese-Scott C, Geer LY, Gwadz M, He S, Hurwitz DI, Jackson JD, Ke Z, Lanczycki CJ, Liebert CA, Liu C, Lu F, Marchler GH, Mullokandov M, Shoemaker BA, Simonyan V, Song JS, Thiessen PA, Yamashita RA, Yin JJ, Zhang D, Bryant SH: CDD: a Conserved Domain Database for protein classification. Nucleic Acids Res 2005, 192-196.

68. Altschul SF, Gish W, Miller W, Myers EW, Lipman DJ: Basic local alignment search tool. J Mol Biol 1990, 215:403-410.

69. Saha S, Raghava GP: Prediction of Continuous B-cell Epitopes in an Antigen Using Recurrent Neural Network. Proteins 2006, 65:40-48.

70. Saha S, Raghava GP: Prediction methods for B-cell epitopes. Methods Mol Biol 2007, 409:387-394

71. Andersen $\mathrm{PH}$, Nielsen M, Lund O: Prediction of residues in discontinuous B cell epitopes using protein 3D structures. Protein Science 2006, 15:2558-2567.

72. Sweredoski MJ, Baldi P: PEPITO: improved discontinuous B-cell epitope prediction using multiple distance thresholds and half sphere exposure. Bioinformatics 2008, 24:1459-1460.

73. Singh $H$, Raghava GP: ProPred: Prediction of HLA-DR binding sites. Bioinformatics 2001, 17:1236-1237.

74. Zhang Q, Wang P, Kim Y, Haste-Andersen P, Beaver J, Bourne PE, Bui HH, Buus S, Frankild S, Greenbaum J, Lund O, Lundegaard C, Nielsen M, Ponomarenko J, Sette A, Zhu Z, Peters B: Immune epitope database analysis resource (IEDB-AR). Nucleic Acids Res 2008, , 36 Web Server: W513-8.

75. Bui HH, Sidney J, Peters B, Sathiamurthy M, Sinichi A, Purton KA, Mothé BR, Chisari FV, Watkins DI, Sette A: Automated generation and evaluation of specific MHC binding predictive tools: ARB matrix applications. Immunogenetics 2005, 57:304-314.

76. Parker KC, Bednarek MA, Coligan JE: Scheme for ranking potential HLA-A2 binding peptides based on independent binding of individual peptide side-chains. J Immunol 1994, 152:163-175 
77. Lundegaard C, Lamberth $\mathrm{K}$, Harndahl M, Buus S, Lund O, Nielsen M: NetMHC-3.0: accurate web accessible predictions of human, mouse and monkey MHC class I affinities for peptides of length 8-11. Nucleic Acids Res 2008, 36 Web Server: W509-12, Epub 2008 May 7.

78. Saha S, Raghava GP: AlgPred: prediction of allergenic proteins and mapping of IgE epitopes. Nucleic Acids Res 2006, W202-209.

79. Fiers MW, Kleter GA, Nijland H, Peijnenburg AA, Nap JP, van Ham RC: Allermatch, a webtool for the prediction of potential allergenicity according to current FAO/WHO Codex alimentarius guidelines. BMC Bioinformatics 2004, 5:133.

80. Fungal RV: Adhesin prediction and immunoinformatics portal for human fungal pathogens. [http://fungalrv.igib.res.in].

doi:10.1186/1471-2164-12-192

Cite this article as: Chaudhuri et al:: FungalRV: adhesin prediction and immunoinformatics portal for human fungal pathogens. BMC Genomics 2011 12:192.

\section{Submit your next manuscript to BioMed Central} and take full advantage of:

- Convenient online submission

- Thorough peer review

- No space constraints or color figure charges

- Immediate publication on acceptance

- Inclusion in PubMed, CAS, Scopus and Google Scholar

- Research which is freely available for redistribution

Submit your manuscript at www.biomedcentral.com/submit 